\title{
Correction: BTI-Tnao38, a new cell line derived from Trichoplusia ni, is permissive for AcMNPV infection and produces high levels of recombinant proteins
}

\author{
Yoshi Hashimoto', Sheng Zhang ${ }^{2}$, Shiying Zhang ${ }^{1}$, Yun-Ru Chen ${ }^{1}$ and Gary W Blissard ${ }^{1 *}$
}

\begin{abstract}
After publication we discovered an error in the identification of the origin of the cell line reported in our article in BMC Biotechnology (2010, 10:50), entitled "Ao38, a new cell line from eggs of the black witch moth, Ascalapha odorata (Lepidoptera: Noctuidae), is permissive for AcMNPV infection and produces high levels of recombinant proteins". Upon analysis of primary A. odorata cultures, we found that they were contaminated with cells of Trichoplusia ni origin. The origin of the Ao38 cell line was determined as T. ni using three marker genes and the Ao38 cell line was renamed BTI-Tnao38. References to the origin of the cell line as Ascalapha odorata should be replaced with "a cell line of Trichoplusia ni origin". The absence of TNCL virus detection in the BTI-Tnao38 (Ao38) cell line was confirmed using a highly sensitive RT-PCR protocol capable of detecting TNCL virus RNA at approximately 0.018 copies/cell. Because of these observations, we have revised the title of the original article to "Correction: BTI-Tnao38, a new cell line derived from Trichoplusia ni, is permissive for AcMNPV infection and produces high levels of recombinant proteins" and two additional authors were added to reflect their contributions to the analysis of this cell line.
\end{abstract}

\section{Correction}

After publication of this work [1], we discovered an error in the identification of the origin of the cell line reported in this study. In this study, we described the isolation and detailed characterization of a cell line that produces high levels of recombinant proteins. In addition, we were unable to detect the presence of the Trichoplusia ni cell line virus (TNCLV), an alphanodavirus that was previously reported in a $T$. $n i$ derived cell line [2]. We reported that the Ao38 cell line was derived from a culture of primary cells of Ascalapha odorata. In the course of our subsequent characterization, we discovered that the source of the Ao38 cell line was not A. odorata as reported, but was instead T. ni. A careful analysis of archived intermediate stages in the production of the cell line indicated that the line resulted from primary

\footnotetext{
* Correspondence: gwb1@cornell.edu

'Boyce Thompson Institute at Cornell University, Tower Road, Ithaca, NY 14853, USA

Full list of author information is available at the end of the article
}

A. odorata cultures that were contaminated with $T$. $n i$ cells. While the source of the contamination is not known with certainty, further analysis suggests that Ao38 cells are likely a clonal derivative of the High Five (Tn5B1-4) cell line. While we stand behind the analysis of the characteristics of this cell line, we are providing a correction to the above study, and we sincerely apologize for any problems or difficulties caused by our error in identification of the origin of this line. Below, we provide representative data establishing the identity of this line as a $T$. $n i$ derived cell line. We also reexamined the cell line for the presence of TNCLV under conditions of defined sensitivity, and provide additional data confirming the absence of detection of the TNCLV alphanodavirus from this line.

To identify the species of origin of the Ao38 cell line, we amplified sequences from three marker genes that have been used to distinguish between and within lepidopteran species: a) mitochondrial cytochrome c oxidase subunit 1 (COI) [3-5], b) internal transcribed spacers

\section{Ciomed Central}




\section{A. COI sequence Alignments}

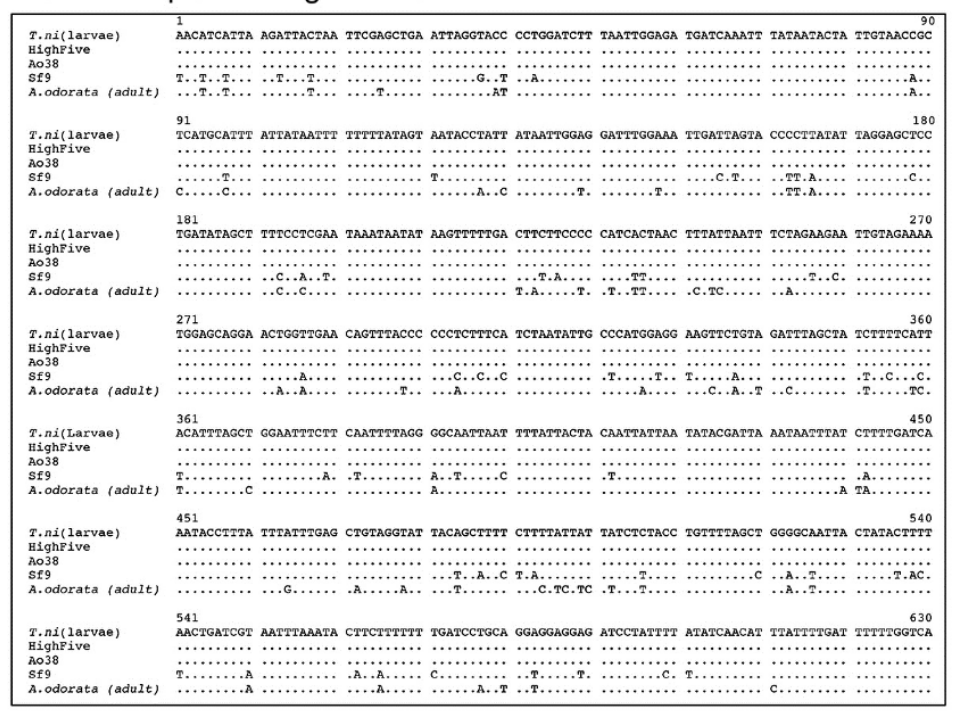

\section{B. ITS1 sequence Alignments}

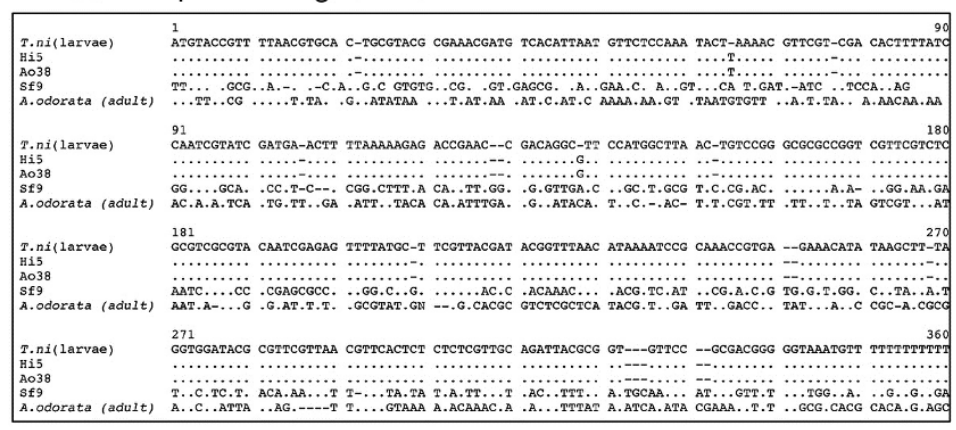

\section{Cadherin Sequence Alignments}

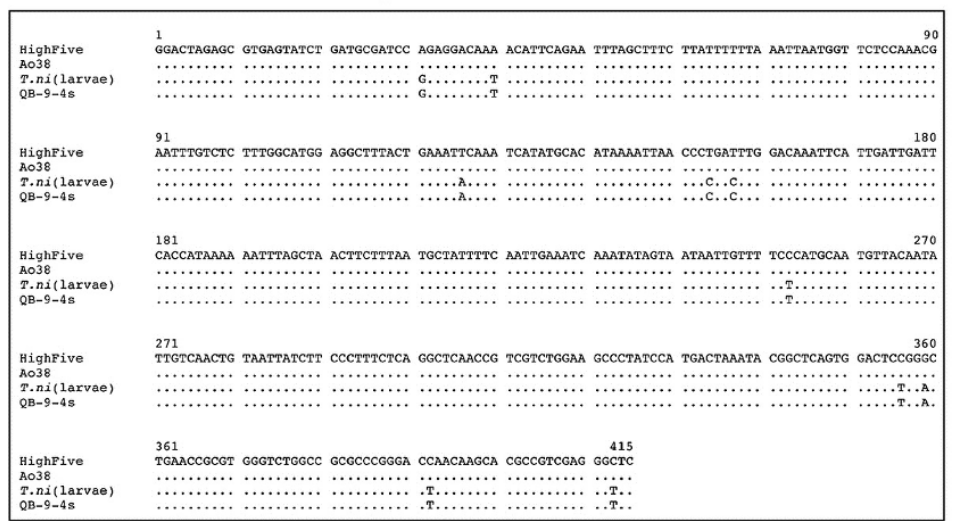

Figure 1 Alignments of marker gene sequences derived from Ao38 cells, and those from reference cell lines and insects. A. Alignment of DNA sequences PCR amplified from the mitochondrial cytochrome oxidase c subunit 1 (COI) gene. Primer pairs LCO1490 (5'GGTCAACAAATCATAAAGATATTGG-3') and HCO2198 (5'-TAAATCTCAGGGTGACCAAAAAATCA-3') [12] were used for PCR amplification of an approximately $658 \mathrm{bp}$ fragment using a previously described method [5] with minor modifications. Reference DNA samples used for comparisons were derived from T. ni larvae (Cornell strain; kindly provided by Dr. Ping Wang), High Five (Tn-5B1-4) cells, Sf9 cells, and an Ascalapha odorata adult. Species identities were also confirmed by analysis using the BOLD database $[3,4,13]$. For all alignments, "." represents nt sequence identity, and differences are indicated by nt abbreviations ( $\mathrm{A}, \mathrm{C}, \mathrm{G}, \mathrm{or}$ T). B. Alignment of sequences amplified from the internal transcribed spacers (ITS) of the nuclear ribosomal 18S-5.8S-28S cistron. Primer pairs ITS1-1 (5'-CCCCATAAACGAGGAATTCC-3') and ITS4 (5'-TCCTCCGCTTATTGATATGC-3') [8] were used for PCR amplification. An amplicon with a size of approximately $1500 \mathrm{bp}$ was amplified. Reference DNA samples were the same as those used for analysis of COI (above). C. Alignment of cadherin fragment sequences from T. ni larvae and cell lines. The cadherin fragment sequences were PCR amplified from the indicated sources using PCR primers PW-206 (5'-CGCTTTGATGGTCTCGTTC-3') and PW-261 (5'-

GCGCTGCTGGGCTTCCTGT-3') as described previously [9]. A 415 nt sequence alignment is shown. Sequences from two T. ni cell lines (High Five and QB-9-4s) and a T. ni larval sample (Cornell strain, provided by Ping Wang) are aligned with the sequence from Ao38 cells. 
(ITS) of the nuclear ribosomal 18S-5.8S-28S cistron [6-8], and c) a cadherin gene [9] (Figure 1). After PCR amplification and sequencing of DNA from selected regions of the COI gene and ribosomal ITS region, we found identical alignment of sequences from Ao38 cells and High Five $(T . n i)$ cells, and nearly identical alignment with sequences from $T . n i$ larvae (Figure $1 \mathrm{~A}$ and $1 \mathrm{~B}$ ), as well as with $T$. $n i$ sequences in the BOLD database $[3,4]$. Control sequences amplified from Sf9 cells and an $A$. odorata adult moth showed substantial variation (Figure $1 \mathrm{~A}$ and $1 \mathrm{~B}, \mathrm{Sf} 9$ and $A$. odorata). Thus, the T. ni origin of the Ao38 cells was established using these sensitive marker genes. To examine the origin of the Ao38 cell line within the species $T$. $n i$, we examined cadherin gene sequences. A fragment of the T. ni cadherin gene sequence that contains an intron, was previously found to be highly polymorphic in sequence [9]. Therefore, we amplified and compared those cadherin sequences from several sources of T. ni. The target cadherin sequence from Ao38 cells was identical to that from High Five cells but differed from that of other T. $n i$ sources. Figure 1C shows 100\% identity between High Five and Ao38 sequences over a 415 bp region of the cadherin sequence. In contrast, sequences derived from larvae of a laboratory strain of T. $n i$ (Cornell strain [10]), and from a recently reported T. $n i$ cell line (QB-9-4s) [11], showed app. 2.4\% sequence divergence over the same region. Thus, the Ao38 line appears to be closely related to, and is likely derived from High Five cells. Based on these data, we decided to rename the Ao38 cell line as BTI-Tnao38.

The alphanodavirus TNCLV is readily detected by RTPCR in growing High Five cells. We previously reported that we were unable to detect TNCLV in the Ao38 cell line by RT-PCR. We therefore performed a careful reexamination of the Ao38 cells for the presence of TNCLV RNA, and measured the sensitivity of our methods. For these studies, we amplified and cloned a $566 \mathrm{nt}$ region of the TNCLV genome, then in vitro transcribed and purified an RNA representing that region of the TNCLV genome. The in vitro transcribed TNCLV RNA was subsequently used for spiking experiments with Sf9 cell RNA, to determine the sensitivity of TNCLV RNA detection in our RTPCR studies (Figure 2). Under these conditions we found that the sensitivity for detection of TNCLV RNA was approximately 53 molecules of TNCLV RNA in the background of total RNA from approximately $3000 \mathrm{Sf} 9$ cells (Figure 2, lanes 3-7). Under these conditions, TNCLV was not detected in RNA isolated from approximately 3000 cells of the Ao38 line (Figure 2, lane 8). In a parallel analysis, Sf9 cells were also negative for TNCLV, as expected (lane 2). Thus, based on this level of sensitivity, we estimate that if TNCLV is present in Ao38 or Sf9 cells, it would be found at less than one TNCLV genome per 50 cells. In contrast to Ao38 and Sf9 cells, TNCLV RNA

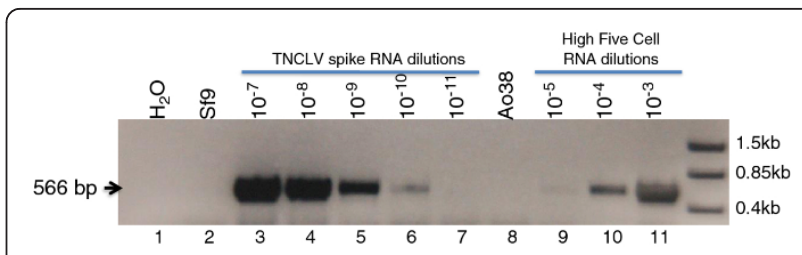

Figure 2 RT-PCR Analysis of cell line RNA for detection of the alphanodavirus, TNCLV. To determine the sensitivity of TNCLV RNA detection, a segment of TNCLV RNA 1 (2368-2933 nt) was synthesized in vitro and used to spike RNA from Sf9 cells. 250 ng of the in vitro RNA fragment was used for a series of serial dilutions $\left(10^{-1}\right.$ to $\left.10^{-12}\right)$ and each diluted RNA fragment sample was added to 250 ng of Sf9 total cell RNA (representing approximately 3000 cells). One-step RT-PCR was performed using the Invitrogen SuperScript III One-Step RT-PCR System with Platinum Taq DNA Polymerase under the following conditions: $30 \mathrm{~min}$ at $45^{\circ} \mathrm{C}$, and $94^{\circ} \mathrm{C}$ for 2 min for 1 cycle; followed by $94^{\circ} \mathrm{C}$ for $15 \mathrm{sec}, 55^{\circ} \mathrm{C}$ for $30 \mathrm{sec}$, and $72^{\circ} \mathrm{C}$ for 45 sec for 40 cycles; then $10 \mathrm{~min}$ at $72^{\circ} \mathrm{C}$. The sensitivity of detection was estimated as approximately 1 TNCLV RNA per 50 cells. Ao38, High Five and Sf9 cell RNAs were examined for TNCLV using the same primers and conditions for RT-PCR as described for spiking experiments. For High Five cells, total cellular RNA (250 ng; representing an estimated 3000 cells) was diluted as indicated $\left(10^{-3}\right.$ to $10^{-5}$ ). For analysis of Ao38 and Sf9 cells, 250 ng of cell RNA was analyzed directly by RT-PCR as described above.

was detected at relatively high levels in High Five cells. Based on the sensitivity of detection in our TNCLV RNA spiking experiment, and the levels of TNCLV RNA detected in dilutions of High Five cell RNA (Figure 2, lanes 9-11), we estimate that TNCLV RNA is present at levels of > 180-300 copies per cell in High Five cells. The marker genes and methods described above may be useful for confirmation or validation of cell lines, and the methods used for alphanodavirus detection may also be useful for laboratories examining $T$. $n i$ or other cell lines suspected to harbor this alphanodavirus.

To reflect the significant contributions of scientists involved in the extended analysis of the origin of the Ao38 cell line, and the analysis of TNCLV RNA detection and sensitivity, Shiying Zhang and Yun-Ru Chen were included as authors of this study.

\section{Acknowledgements}

The authors are grateful to Ping Wang for providing data and expertise on the analysis of cadherin gene sequences.

\section{Author details}

'Boyce Thompson Institute at Cornell University, Tower Road, Ithaca, NY 14853, USA. ${ }^{2}$ Proteomics and Mass Spectrometry Facility, Cornell University, Tower Road, Ithaca, NY 14853, USA.

\section{Authors' contributions}

GWB conceived the initial project. YH developed methods and designed and performed experiments for cell line generation. GWB and $\mathrm{YH}$ designed experiments on cell line characterization, virus infectivity, and recombinant protein production. YH performed those experiments and GWB and YH analyzed the data and wrote the manuscript. Sheng $Z, Y H$, and GWB designed glycan analysis studies. Sheng $Z$ performed the experiments, 
analyzed glycan data, and wrote a portion of the manuscript. Sheng Z, YH, and GWB edited, read and approved the original manuscript. YC and Shiying $Z$ designed experiments and performed analysis of species-specific marker genes. Shiying $Z$ and GWB designed experiments on alphanodavirus detection and Shiying $Z$ performed the experiments and analyzed the data. GWB wrote the correction and all authors edited, read and approved the correction.

Received: 22 March 2012 Accepted: 24 April 2012

Published: 24 April 2012

\section{References}

1. Hashimoto Y, Zhang S, Blissard GW: Ao38, a new cell line from eggs of the black witch moth, Ascalapha odorata (Lepidoptera: Noctuidae), is permissive for AcMNPV infection and produces high levels of recombinant proteins. BMC Biotechnol 2010, 10(1):50.

2. Li T-C, Scotti PD, Miyamura T, Takeda N: Latent Infection of a new Alphanodavirus in an insect cell line. J Virol 2007, 81(20):10890-10896.

3. Ratnasingham S, Hebert PDN: BOLD: The Barcode of Life Data System. Molecular Ecology Notes 2007 [http://www.barcodinglife.org], doi: 10.1111/ j.1471-8286.2006.01678.x.

4. Hebert PD, Dewaard JR, Landry JF: DNA barcodes for $1 / 1000$ of the animal kingdom. Biol Lett 2010, 6(3):359-362.

5. Hebert PD, Cywinska A, Ball SL, de Waard JR: Biological identifications through DNA barcodes. Proc Biol Sci/The Royal Soc 2003, 270(1512):313-321

6. Nieto Feliner G, Rossello JA: Better the devil you know? Guidelines for insightful utilization of nrDNA ITS in species-level evolutionary studies in plants. Mol Phylogenet Evol 2007, 44(2):911-919.

7. YEH S-C, LEE S-T, WU C-Y, WANG C-H: A cell line (NTU-MV) established from Maruca vitrata (Lepidoptera: Pyralidae): Characterization, viral susceptibility, and polyhedra production. J Invertebr Pathol 2007, 96(2):138-146.

8. Wu CY, Lin HF, Wang CH, Lo CF: Identification of insect cell lines and cellline cross-contaminations by nuclear ribosomal ITS sequences. J Appl Entomology 2011, 135(8):601-610.

9. Zhang $X$ : Sequence variation in cadherin alleles from the cabbage looper, Trichoplusia ni. M S. Thesis. Cornell University; 2007.

10. Tiewsiri K, Wang P: Differential alteration of two aminopeptidases $\mathrm{N}$ associated with resistance to Bacillus thuringiensis toxin Cry1 Ac in cabbage looper. Proc Natl Acad Sci USA 2011, 108(34):14037-14042.

11. Shan M, Zhang SY, Jiang L, Ma M, Li GX: Susceptibility to AcMNPV and expression of recombinant proteins by a novel cell clone derived from a Trichoplusia ni QAU-BTI-Tn9-4s cell line. Virol Sin 2011, 26(5):297-305.

12. Folmer $\mathrm{O}$, Black M, Hoeh W, Lutz R, Vrijenhoek R: DNA primers for amplification of mitochondrial cytochrome c oxidase subunit I from diverse metazoan invertebrates. Mol Mar Biol Biotechnol 1994, 3(5):294-299.

13. Lukhtanov VA, Sourakov A, Zakharov EV, Hebert PD: DNA barcoding Central Asian butterflies: increasing geographical dimension does not significantly reduce the success of species identification. Mol Ecol Resour 2009, 9(5):1302-1310.

\section{doi:10.1186/1472-6750-12-12}

Cite this article as: Hashimoto et al:: Correction: BTI-Tnao38, a new cell line derived from Trichoplusia ni, is permissive for AcMNPV infection and produces high levels of recombinant proteins. BMC Biotechnology 2012 12:12

\section{Submit your next manuscript to BioMed Central and take full advantage of:}

- Convenient online submission

- Thorough peer review

- No space constraints or color figure charges

- Immediate publication on acceptance

- Inclusion in PubMed, CAS, Scopus and Google Scholar

- Research which is freely available for redistribution

Submit your manuscript at www.biomedcentral.com/submit
Biomed Central 